\title{
Growth patterns in biomass and size structure of Mytilus galloprovincialis cultivated in the Ría de Arousa (north-west Spain)
}

\author{
José M.F. Babarro*, Uxío Labarta and María José Fernández-Reiriz \\ CSIC Instituto de Investigaciones Marinas, Eduardo Cabello 6, 36208 Vigo, Spain. \\ *Corresponding author, e-mail: jbabarro@iim.csic.es
}

\begin{abstract}
Growth of seed mussel Mytilus galloprovincialis (Bivalvia: Mytilidae) from two origins (rocky shore and collector ropes) placed on raft culture was compared. Mussel seed were cultivated following the commercial culture phases commonly used in Galician Rías: (a) from seeding to thinning-out and (b) from thinning-out to harvest. Differences in growth rate were clearly related to the phase of the culture, being significant during the first phase from seeding to thinning out (January-November 1998). In the latter phase, weight values observed for collector rope mussels were significantly higher than those for rocky shore individuals $(0.65 \mathrm{vs} 0.45 \mathrm{~g}$ total dry weight, $0.11 \mathrm{vs} 0.08 \mathrm{~g}$ tissue dry weight, $0.53 \mathrm{vs} 0.37 \mathrm{~g}$ shell dry weight and 0.09 vs $0.07 \mathrm{~g}$ tissue organic weight per month, respectively; $P<0.001)$. Neither shell length nor weight (soft tissue or shell) growth rate showed differences during the second phase of the culture from thinning out to harvest (November 1998-July 1999; $P>0.05$ ). Nevertheless, in terms of output, the higher number of individuals above $70 \mathrm{~mm}(77 \%$ vs $61 \%)$ and the heavier soft tissue (and total) weight $(23-30 \%)$ for collector ropes mussels when compared to rocky shore ones at harvest, highlighted the importance of choosing the former stock. Condition index (CI) did not differ at the onset of the culture between both origins $(P>0.05)$, but mussels from collector ropes showed significantly higher values than those from the rocky shore from May to November $1998(P<0.001)$ before thinning-out was undertaken. No differences in CI were observed from thinning out to harvest between both types of mussels $(P>0.05)$. Although both populations showed normal (unimodal) size distributions at the onset of the culture, mussels from rocky shore origin fitted better to bimodal profiles throughout the first phase of the culture. These bimodal distributions of rocky shore population did disappear during the second phase suggesting a more uniform size spectrum as a consequence of the thinning out process, which involves a selection of size.
\end{abstract}

\section{INTRODUCTION}

Cultivation of the mussel (Mytilus galloprovincialis Lmk.) in Galicia (north-west Spain) requires a large amount of seed in order to support a mussel production of 200,000 tonnes per year (Pérez Camacho et al., 1995). Mussel farmers usually obtain this seed from two very different origins: coastal stocks from the rocky shoreline and collector ropes suspended from cultivation rafts. The mussel cultivation has two phases defined as pre-fattening (from seeding to thinning out) and fattening (from thinning out to harvest) (see Pérez Camacho et al., 1995, for more details). The thinning out process is carried out when individuals reach a size of $\sim 5 \mathrm{~cm}$ and three new ropes can be established from each rope, allowing the mussels to grow until they reach commercial size $(7-10 \mathrm{~cm}$ ) (Pérez Camacho et al., 1991).

Many studies have reported to what extent local environmental conditions can impact significantly on the physiology of bivalves, and therefore modify the growth potential (Bayne \& Widdows, 1978; Widdows et al., 1984; Navarro et al., 1991 among others). Adaptation of individuals to their habitats in turn made it possible to establish effects linked to origin when they are transplanted to new environmental and/or nutritional conditions, by observing differences in physiology with local (native) populations that could persist for some time (Widdows et al., 1984; Iglesias et al., 1996). The growth potential of both seed mussels originally from such different habitats (rocky shore and collector ropes mussels) has been dealt with in several studies recently, which in turn have reported controversial results. On one hand, Pérez Camacho et al. (1995) and Babarro et al. (2000a) have observed differences in growth rate and condition index of mussels in the first phase of the culture (from seeding to thinning out). They attribute this to the origin of seed, with growth rate being higher for collector ropes mussels as compared with rocky shore individuals. On the other hand, Fuentes et al. (1998) have reported no differences in growth potential between both sources of seed when placed on the raft. Nevertheless, they recommended seed from collector ropes since it reaches greater length and/or weight than that of rocky shore due to different initial size of the two types of mussels.

Dickie et al. (1984), Page \& Hubbard (1987) and Fuentes et al. (1992) have all established that the origin of the seed has a significant effect on mortality rates, although not on growth. However, Peterson \& Beal (1989) and Rawson \& 
Hilbish (1991) have observed a significant effect of origin on growth, which they explain as being due to genetic differences. However, with our experimental design the hypothetical interference of genetic factors on our results was considered of minor importance (see Pérez Camacho et al., 1995; Babarro et al., 2000a).

The aim of this study was to re-investigate the growth potential of both sources of mussels commonly used in Galician raft culture during the whole cultivation period from seeding $(\approx 20 \mathrm{~mm})$ to harvest $(\approx 70 \mathrm{~mm})$ as an extension of our previous surveys which considered only the first phase of the culture. From the present results and previous experimental data from mussel raft culture, different hypotheses will be formulated which might explain variability of growth potential between both types of mussels.

\section{MATERIALS AND METHODS}

\section{Experimental design}

Seed of Mytilus galloprovincialis Lamarck, approximately $20 \mathrm{~mm}$ long, was gathered from both rocky shore coastline and raft collector ropes in the mid-to-outer area of the Ría de Arousa (Galicia, north-west Spain) in January 1998. Both sources of seed, from the same year-class, came from the spawning period of the previous autumn. The sampling locations were $2 \mathrm{~km}$ away from each other and individuals from both origins were obtained from precleaned intertidal and collector areas. The sampling procedure was as described by Babarro et al. (2000a). Experimental culture, which was carried out on a raft usually employed for the culture in the Ría de Arousa $\left(500 \mathrm{~m}^{2}\right)$, commenced one day after sampling and in winter in order to minimize any possible advantages that collector ropes seed may have as a result of its better adaptation to cultivation on the raft. The experiment lasted until July 1999 (520 days), thus covering both phases of the culture. The pre-fattening phase lasted from January to November 1998. In this period both mussel seed reached a size $(50-60 \mathrm{~mm})$ to carry out thinning process which has two main objectives: reduce the density of the culture (individuals $/ \mathrm{m}$ of rope) due to biomass increase by preparing new ropes from each mussel seed and discard small individuals in order to get a uniform size at harvest (see Perez Camacho et al., 1991). The fattening phase lasted from November 1998 to July 1999, after which the mussels were ready to harvest. Ten cultivation ropes $(12 \mathrm{~m})$ were used, five for each type of seed, alternately placed and having a density of $12 \mathrm{~kg}$ of seed per rope $(1 \mathrm{~kg} / \mathrm{m}$ of rope or 1300 individuals $/ \mathrm{m}$ of rope). Sampling was performed by removing mussels from adjacent ropes at an average depth of 2-4 metres for both types of seed. The density used at the onset of the second phase (fattening) was 200 individuals/m of rope for both types of mussel seed.

Initial mean ( $\pm \mathrm{SD}$ ) shell length values were $21.2 \pm 8.5 \mathrm{~mm}$ for the seed from collector ropes and $19.5 \pm 7.9 \mathrm{~mm}$ from the rocky shore ones obtained from size distribution data. Mean total dry weights (shell plus soft tissues) were $0.37 \pm 0.11$ and $0.35 \pm 0.09 \mathrm{~g} /$ individual, respectively. No significant differences were observed for length and total dry weight between both types of seed at the onset of the experiment (analysis of variance (ANOVA); $P>0.05$ ).

\section{Mussel sampling}

Duplicate samples of 200-300 individuals were taken from adjacent ropes, which corresponded, to both types of mussel seed. Individual mussel length $(\mathrm{L})$ was measured to the nearest $1 \mathrm{~mm}$ using callipers and each sample was divided into 1-mm length classes. The sampling episodes throughout the experimental study corresponded to the following dates for 1998: 28 January (seeding), 11 March, 7 May, 3 June, 1 July, 11 November (thinning out process) and 1999: 28 April, 26 May, 7 July (harvest). Mean shell length values $( \pm \mathrm{SD})$ were obtained by statistical analysis of the size distributions following a previous study (Babarro et al., 2000a). Sub-samples of 5-15 mussels each were taken from five to six length classes covering the entire size range and used to determine total dry weight $\left(\mathrm{DW}_{\text {total }}\right)$ and organic weight of soft tissues $\left(\mathrm{OW}_{\text {tissue }}\right)$. After cutting adductor muscles and allowing the intrapallial water to drain by placing the mussels with their ventral edge on filter paper, tissues were dissected and both shell valves $\left(\mathrm{DW}_{\text {shell }}\right)$ and soft tissues $\left(\mathrm{DW}_{\text {tissue }}\right)$ were weighed after drying at $100^{\circ} \mathrm{C}$ until constant weight was obtained. Soft tissues were ashed at $450^{\circ} \mathrm{C}$ for $48 \mathrm{~h}$ to determine $\mathrm{OW}_{\text {tissue }}$ with an accuracy of $0.01 \mathrm{~g}$.

Condition index of the animals (CI) was calculated as the individual dry weight per volume. As an index of (shell) volume the length to the third power was used.

\section{Data analysis}

After collection, the shell length of about 200-300 mussels (in duplicate) from each origin was measured. Frequency of different shell length classes was monitored at each sampling point. After testing both replicates as non-significantly different ones, the number of individuals was summed as one sample. Size distribution data were log-transformed prior to the analysis if this improved the homogeneity of variances. Bimodal distributions were tested by fitting on the residuals of the least-squares regression both the normal distribution function and a bimodal function given by

$\mathrm{P}=\mathrm{q} \mathrm{N}\left(\mu_{1}, \sigma_{1}\right)+(1-\mathrm{q}) \mathrm{N}\left(\mu_{2}, \sigma_{2}\right)$,

where $\mathrm{q}$ is a constant between 0 and $1, \mathrm{~N}$ is the normal distribution with mean $\mu$ and standard deviation $\sigma$. The distribution of a variable was considered bimodal if the bimodal model gave a significantly better fit than the unimodal model, as determined by the log-likelihood ratio (which explicitly takes into account the increase in the number of parameters) and according to this is shown in Figure 1. In order to obtain weight values corresponding to the mean shell length values throughout the experiment, regression models were calculated for the logarithm of total dry weight $\left(\log \mathrm{DW}_{\text {total }}\right)$, soft tissue dry weight (log $\left.\mathrm{DW}_{\text {tissue }}\right)$, shell dry weight $\left(\log \mathrm{DW}_{\text {shell }}\right)$ and soft tissue organic weight (log $\left.\mathrm{OW}_{\text {tissue }}\right)$ vs logarithm of length (log L) relationships from data obtained for five or six length classes covering the entire length class ranging from 10-15 $\mathrm{mm}$ above and below the mean length: $\log \mathrm{W}=$ $\log \mathrm{a}+\mathrm{b} \log \mathrm{L}$.

Growth equations for average shell length were described according to the model of von Bertalanffy (VB): 

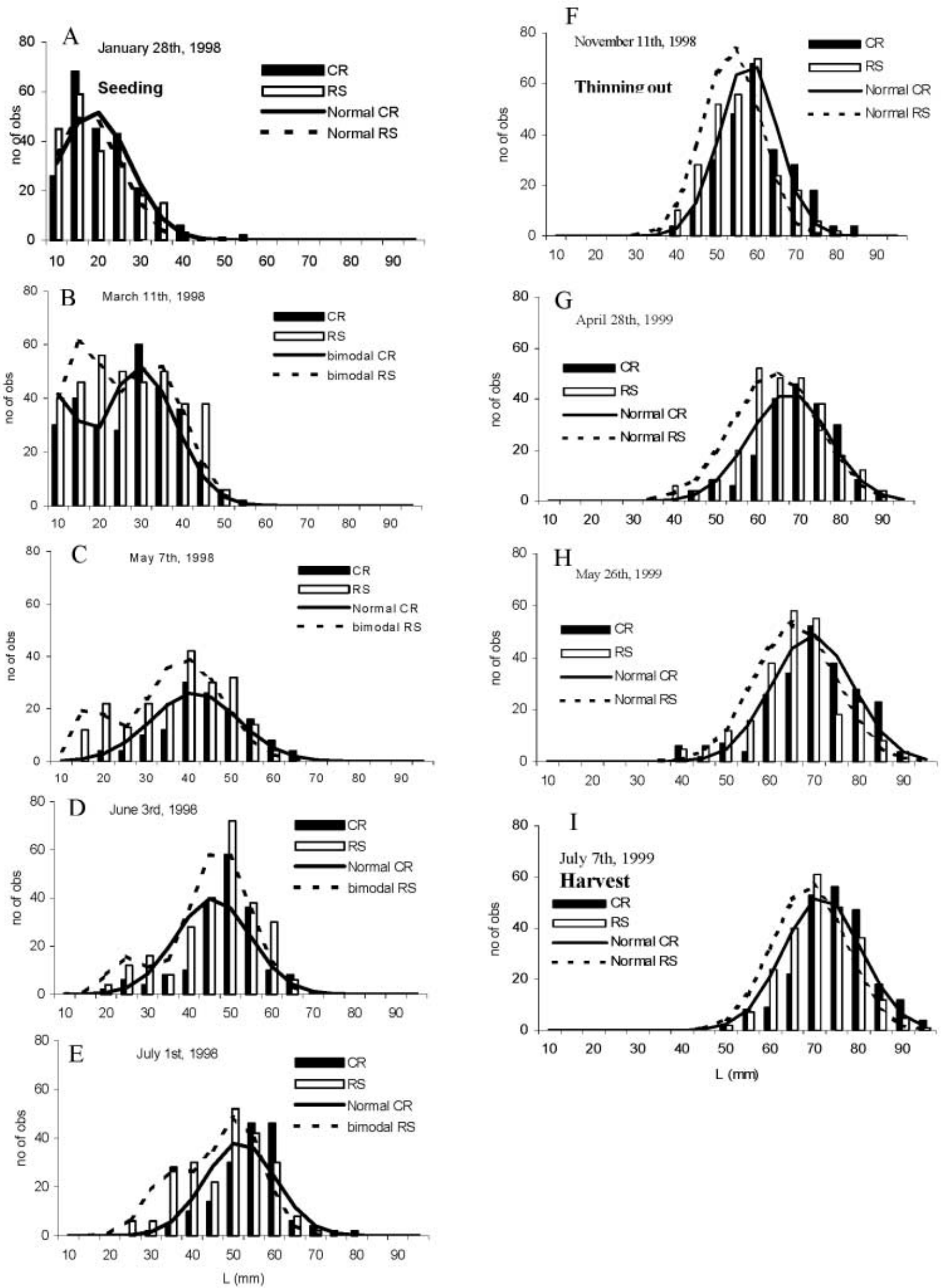

Figure 1. Size (shell length)-frequency distributions (A-I) for both types of mussels during the whole experimental period. Size distributions were fitted to normal (unimodal) and bimodal equations depending on the $P$ values obtained for each case (see Materials and Methods). CR, collector ropes; RS, rocky shore.

$\mathrm{L}_{\mathrm{t}}=\mathrm{L}_{\infty}\left[1-\mathrm{e}^{-\mathrm{k}\left(\mathrm{t}-\mathrm{t}_{0}\right)}\right]$,

where $\mathrm{L}_{\mathrm{t}}$ is the shell length at time $\mathrm{t}$ (months), $\mathrm{L}_{\infty}$ is the maximum size, $\mathrm{k}$ is the instantaneous growth rate. All experimental data obtained for mass values (see above) from the whole cultivation period (January 1998-July 1999; $\mathrm{N}=90$ ), were used to obtain allometric coefficients for the total dry weight vs shell length relationship 
$\left(\mathrm{DW}_{\mathrm{total}}=\mathrm{a} \mathrm{L^{ \textrm {b } }}\right)$. Analysis of covariance (ANCOVA) was used to make a comparison of the equations of both origins. The latter allometric coefficients (b) were used to fit total dry weight curves according to the Gompertz model (Dame, 1996) which gave better regression coefficients:

$\mathrm{DW}_{\mathrm{t}}=\mathrm{DW}_{\infty}\left[\mathrm{e}^{-\mathrm{e}^{(-\mathrm{k} \times \mathrm{t})}}\right]^{\mathrm{b}}$,

where $\mathrm{DW}_{\mathrm{t}}$ is the total dry weight at time $\mathrm{t}$ (months), $\mathrm{DW}_{\infty}$ is the maximum weight, $\mathrm{k}$ is the instantaneous growth rate and $\mathrm{b}$ is the allometric coefficient.

Growth rate was calculated in both phases of the culture (from seeding to thinning out and from thinning out to harvest) on a monthly basis (mm or grams per month) from VB or Gompertz curve fitting in order to compare values for both sources of seed and phases of culture. Confidence intervals for the difference in weight between months of the cultivation period studied that gives the growth rate for each stage was given by the formula:

$\mathrm{X}_{\mathrm{t}+1}-\mathrm{X}_{\mathrm{t}} \pm t_{1-\alpha / 2, \mathrm{k}} \operatorname{Sp} \sqrt{ }\left(1 / \mathrm{N}_{\mathrm{t}+1}+1 / \mathrm{N}_{\mathrm{t}}\right)$

(see Babarro et al., 2000a), where $\mathrm{X}_{\mathrm{t}+1}$ and $\mathrm{X}_{\mathrm{t}}$ are the mean shell/mass values at each end of the interval, $\mathrm{Sp}^{2}$ is the variance at each end of the interval, $\mathrm{N}_{t+1}$ and $\mathrm{N}_{\mathrm{t}}$ are the number of samples at each end of interval, and $t_{1-\alpha / 2, \mathrm{k}}$ is the Student $t$-distribution value with $95 \%$ confidence and $\mathrm{k}$ degrees of freedom $\left(\mathrm{k}=\mathrm{N}_{\mathrm{t}+1}+\mathrm{N}_{\mathrm{t}}-2\right)$. Percentage of mussels (frequency) above and below 20, 55 and $70 \mathrm{~mm}$ as characteristic shell length values of seeding, thinning out and harvest procedures in the mussel culture, respectively, was obtained from the total number of animals sampled (duplicate samples of 200-300 mussels; see above).

Comparison of mean values of growth rate, condition index, and frequency of mussels for each size range was carried out with an ANOVA. Homogeneity of variances was tested by the Bartlett test (Snedecor \& Cochran, 1989) and correction for heterogeneity (when required) was performed by reciprocal or logarithmic transformation data. In cases when homogeneity was not obtained after these transformations were carried out, the KruskalWallis non-parametric test was used.

\section{RESULTS}

Size distributions

Figure 1 illustrates the size distribution analysis for both types of mussels under culture conditions. Although size distribution is similar (unimodal) for both sources of mussel seed at the onset of the experiment (January 1998), those individuals from rocky shore origin presented a more heterogeneous spectrum during the first phase of the culture. Bimodal distribution fitted better during this first phase in case of rocky shore mussels when compared with unimodal curves, which in turn means that a smaller mode value was observed for the latter population (Figure 1). Conversely, the bimodal fitting distribution was absent during the second phase of the culture, both populations being fitted to unimodal (normal) curves (Figure 1).
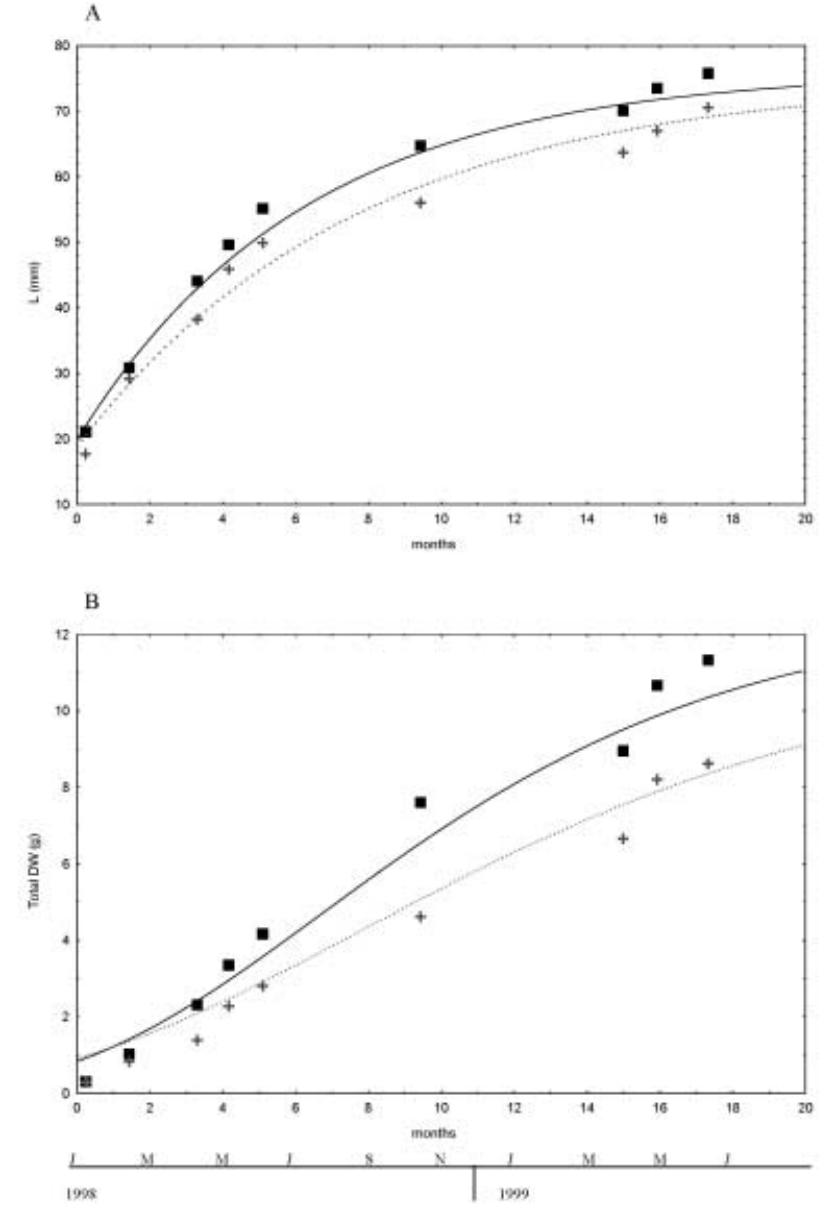

Figure 2. Growth curves estimated according to von Bertalanffy and Gompertz models (see Materials and Methods) for shell length ( $\mathrm{L} \mathrm{mm}, \mathrm{A})$ and total dry weight (Total DW g, B), respectively, during the experimental period (January 1998-July 1999). Equations are shown in the text. Collector ropes mussels, squares and continuous line; rocky shore mussels, crosses and dashed line.

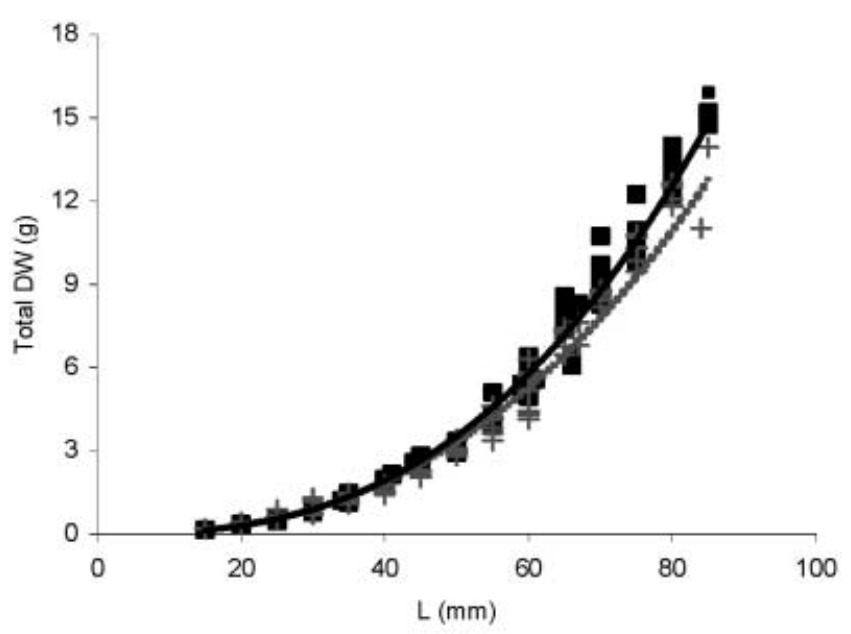

Figure 3. Allometric relationship total dry weight vs shell length for both types of mussels during the whole experimental period (November 1998-July 1999). Equations are shown in the text. For symbols and fitting curves see Figure 2. 


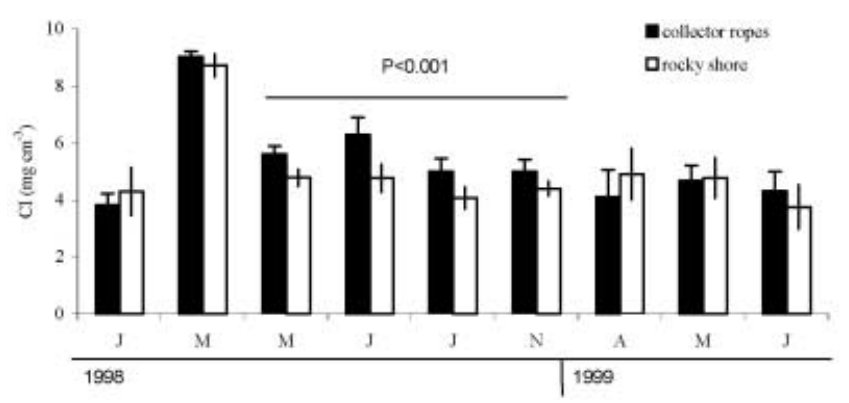

Figure 4. Fluctuation of condition index values $\left(\mathrm{mg} \times \mathrm{cm}^{-3}\right)$ for collector ropes and rocky shore mussels throughout the cultivation period. ANOVA results are indicated when significant values are obtained.

\section{Growth curves and condition index}

Figure 2A illustrates the corresponding growth curves of shell length for both groups of mussels throughout the experimental period. Both curves have been fitted according to the VB model (see Materials and Methods):

Collector ropes $\mathrm{L}=$

$$
76.16\left[1-\mathrm{e}^{-0.16(\mathrm{t}+1.89)}\right] \mathrm{N}=9 ; r^{2}=0.987 ; P<0.001
$$

Rocky shore $\mathrm{L}=$

$$
75.02\left[1-\mathrm{e}^{-0.13(\mathrm{t}+2.22)}\right] \mathrm{N}=9 ; r^{2}=0.990 ; P<0.001
$$

All data set from seeding to harvest of both (shell length and total dry weight) size parameters have been used to


Figure 5. Growth rate ( $\mathrm{mm}$ or $\mathrm{g} / \mathrm{month}, \mathrm{A}-\mathrm{E})$ of mussels from both sources of seed and during the two phases of the culture. ANOVA results are indicated when significant values are obtained. 


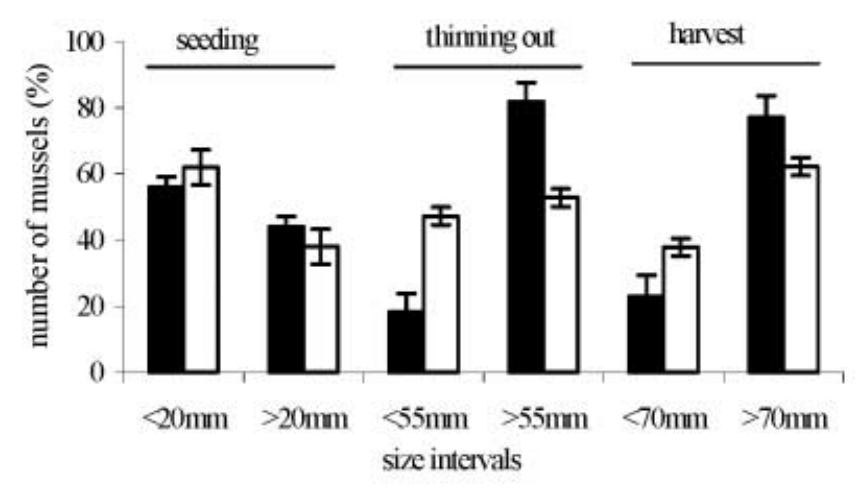

- collector ropes Drocky shore

Figure 6. Percentage of number of mussels (frequency) above and below 20, 55 and $70 \mathrm{~mm}$ as characteristic shell length values of seeding, thinning out and harvest procedures in the experimental mussel culture, respectively.

establish total dry weight $\left(\mathrm{DW}_{\text {total }}\right)$ vs length $(\mathrm{L})$ relationship. This relationship is illustrated in the Figure 3 and can be described as follows:

Collector ropes $\mathrm{DW}_{\text {total }}=$

$$
9.10 \times 10^{-5} \mathrm{~L}^{2.72 \pm 0.06} \mathrm{~N}=90 ; r^{2}=0.994 ; P<0.001
$$

Rocky shore $\mathrm{DW}_{\text {total }}=$

$$
1.61 \times 10^{-4} \mathrm{~L}^{2.53 \pm 0.03} \mathrm{~N}=90 ; r^{2}=0.981 ; P<0.001
$$

The ANCOVA performed on the transformed allometric equations showed significantly higher slope value for collector ropes individuals as compared with rocky shore specimens $(t=10.938 ; \mathrm{df}=176 ; P<0.001)$. Therefore, it was possible to establish the corresponding weight (total dry weight) curves according to the Gompertz model by using allometric coefficients obtained before (Figure 2B):

Collector ropes DW =

$$
12.67\left[\mathrm{e}^{-\mathrm{e}^{(-0.15 t)}}\right]^{2.72} \mathrm{~N}=9 ; r^{2}=0.988 ; P<0.001
$$

Rocky shore DW =

$$
11.49\left[\mathrm{e}^{-\mathrm{e}^{(-0.12 \mathrm{t})}}\right]^{2.53} \mathrm{~N}=9 ; r^{2}=0.980 ; P<0.001
$$

Fluctuation of condition index values (CI) of both mussel groups throughout the experimental period is presented in Figure 4. No significant differences $(P>0.05)$ were observed at both initial (January 1998) and March sampling points, but mussels from collector ropes presented higher CI from May to November 1998 when compared with rocky shore specimens $(P<0.001)$. Both types of mussels showed similar CI values during the second phase from thinning out to harvest $(P>0.05$; Figure 4$)$, ranging between $3.7-5.0$.

Growth rate vs phase of culture and seed origin. Frequency of different mussel sizes throughout the experimental period

Collector ropes mussels grew at a rate of $4.16 \mathrm{~mm} /$ month for shell length values during the first phase of the culture from seeding to thinning out (Figure 5). During the same period, mussels from rocky shore origin increased the shell length at a rate of $3.89 \mathrm{~mm} /$ month. These values were not significantly different $(P>0.05)$. However, more pronounced differences were observed when weights are taken into account $(P<0.01)$, being for collector ropes mussels $38-45 \%$ higher values than those from rocky shore (see Figure 5 for different weights). During the second phase of the culture from thinning out to harvest, no differences were observed in growth rate values between both groups of mussels, neither in shell length nor in weights. Despite these similar growth rate values for the second phase of culture, mussels from collector ropes were clearly heavier at the end of the experiment (see Figure 2B) as a consequence of differences recorded at the end of the first phase.

Figure 6 illustrates the frequency of different mussel sizes as a percentage of individuals above and below a certain shell length that can be considered specific for seeding $(20 \mathrm{~mm})$, thinning out $(55 \mathrm{~mm})$ and harvest $(70 \mathrm{~mm})$ procedures of the mussel culture. Most of the mussels from collector ropes can be grouped above $55 \mathrm{~mm}$ $(82 \%)$ at the thinning out process and above $70 \mathrm{~mm}(77 \%)$ at harvest. However, mussels from the rocky shore above $55 \mathrm{~mm}$ clearly represented a lower frequency at both thinning out $(53 \%)$ and harvest $(61 \%)$ procedures, respectively $(P<0.01)$. No differences between both groups of mussels were observed at the seeding stage $(P>0.05)$, values ranged between 56-63\% below $20 \mathrm{~mm}$ (Figure 6).

\section{DISGUSSION}

Results of this study pointed out the significant influence of seed origin of Mytilus galloprovincialis on growth rate when placed on a raft culture, though differences between both types of mussels were related to the phase of the culture, being only significant from seeding to thinning out (first phase; Figure 5). This result is in agreement with previous studies, which were carried out only on the first phase of culture (Pérez Camacho et al., 1995; Babarro et al., 2000a). Moreover, in the latter studies it was also reported that differences are more pronounced in terms of weight than shell length in the period from seeding to thinning out $(38-45 \%$ heavier mussels from collector ropes as compared with rocky shore ones; Figure 5, the present study). When we extended the experiment to the second phase (from thinning out to harvest), no differences were observed in shell length or weight growth rate values for both groups of mussels (Figure 5). However, in terms of output, mussels from collector ropes were significantly heavier at the end of the experiment (Figure 2B), as a consequence of growth rates at the first phase. The total mass values of the latter source of seed were $2 \mathrm{~g}$ heavier (3 mm longer shell length) than rocky shore ones at harvest (Figure 2B), and more significantly, the percentage of individuals above $70 \mathrm{~mm}$ was significantly higher for collector ropes $(77 \%)$ as compared with rocky shore ones $(61 \%$ ) (Figure 6), confirming the better performance of the culture when mussels from collector ropes are selected. In a recent study, Fuentes et al. (1998) also found heavier and longer mussels from collector ropes $(3.6 \mathrm{~g}$ and $6 \mathrm{~mm}$, respectively) at the end of the culture period as compared with rocky shore individuals under raft culture. Nevertheless, a closer look at the latter study, indicates that yield differences between both sources of seed could be a result of differences in shell length and weight at thinning out process $(14 \mathrm{~mm}$ longer and $4.6 \mathrm{~g}$ heavier mussels from collector ropes) or at seeding $(15 \mathrm{~mm}$ longer; no weight 
values). In our case, we also observed significant differences at the thinning out phase (mussels from collector ropes were $4 \mathrm{~mm}$ longer and $1.8 \mathrm{~g}$ heavier) but this was not the case at the seeding process (see Materials and Methods). This starting condition was an important prerequisite of our experimental design in order to avoid initial differences, which can have important influence on growth patterns in a comparative study. As was the case in previous studies, initial size (weight/length) had no effect on subsequent growth, either by testing the results statistically or by minimizing weight differences at the onset of the experiment (Pérez Camacho et al., 1995 and Babarro et al., 2000a). This is important since differences in initial length or age can account for a high percentage of the variance (see Sukhotin \& Maximovich, 1994).

In recent years, different studies have been carried out in order to explain the basis of the different growth potential reported for both types of mussels during the first phase of the culture. Already suggested by Pérez Camacho et al. (1995), we assumed a physiological adaptation response of each source of seed to its habitat, which in turn might cause both types of seed at the start of raft culture to be in a different physiological state (Babarro et al., 2000a). These responses have been defined by Mallet et al. (1987) as the ecological memory of the individuals with regard to the original habitat when they are placed in a different environment.

We have established differences in physiological responses between both sources of mussels, which may contribute to the observed differences in growth potential under raft culture. First, mussels from collector ropes showed higher clearance/ingestion rates (Babarro et al., 2000b) and absorption efficiency (Babarro, 1998) as compared with rocky shore individuals at the onset of the culture. However, specimens from rocky shore habitat were able to adjust their physiological responses for ingestion rate and absorption efficiency to that of collector ropes mussels 15 and 80 days after translocation, respectively. Secondly, with respect to energy-consuming activities, estimated as oxygen consumption rate values, rocky shore specimens showed higher values when compared with collector ropes ones during the first half (110 days) of the seeding-thinning out phase (Babarro et al., 2000c). As a consequence individuals will allocate more energy to metabolic maintenance and therefore less energy remains available for somatic growth.

Nevertheless, considering both energy acquisition and metabolism aspects, the differences observed between origins were restricted to the first half of the first phase of the culture whereas differences in growth rate further increased after this period in the present study. Results of size distribution profiles for the rocky shore population in the present study might be related to the pattern of physiological behaviour for the latter population when placed under raft culture (see above). Although at the onset of the culture both sources of seed had a similar (unimodal) distribution, heterogeneity was a feature of rocky shore population during the first phase of the culture (Figure 1). The fact that adaptation of rocky shore mussels (as compared with those from collector ropes) to culture conditions in terms of both energy acquisition and expenditure values took weeks and months respectively (see above), resulting in a lower scope for growth (Babarro,
1998), might be responsible for the changes observed in the size spectrum of rocky shore mussels throughout the first phase of the culture. Moreover, at the end of this first phase, a significantly higher number of mussels from collector ropes that could be grouped above $55 \mathrm{~mm}(82 \%)$ at the thinning out process as compared with rocky shore ones $(53 \%$, Figure 6) confirmed collector ropes ones as better performers. The disappearance of the bimodal distributions in rocky shore specimens during the second phase of the culture must be interpreted as a consequence of thinning out process itself since this operation involves a selection of individuals from both origins by the size named 'parrillado' in order to get a uniform size spectrum for commercial purposes at harvest (Pérez Camacho et al., 1991).

Recently published results have reported to what extent increased acquisition, modified allocation and metabolic efficiency models can account for different growth potential of both 'selected' and 'non selected, control' genetic categories of the Sydney rock oyster Saccostrea commercialis (see Bayne, 1999, 2000; Bayne et al., 1999 for a review). The authors point out that a single analysis of the physiological parameters that contribute to growth (energy balance equation) would be 'inadequate' to identify the cause of differences in growth rate. Additionally, control of metabolic processes might clarify and help to understand those differences. Although these suggestions were made to explain genetically correlated variability in growth rate, it is also possible that a combination of physiological and/ or, to a greater extent, metabolic components is also responsible for the different growth rates in our study. Our last studies suggest such a link, though differences in allocation of energy to other energy-demanding processes like gametogenesis/reproduction, can not be rejected with our experimental design. The latter processes, however, might be considered of less importance during the high and constant growth period from seeding to thinning out when differences in growth rate were already reported, but would be more significant when individuals are older due to age dependence of energy allocation patterns between reproduction and somatic growth. We might hypothesize that during the second half of the seeding-thinning out phase, mussels from collector ropes were somehow metabolically more efficient than rocky shore ones resulting in a higher gain of weight during the more favourable summer period. Indeed, size distribution profiles during the first phase of the culture and condition index differences from May to November 1998 (see Figures 1 and 4, respectively) suggested such a link. The challenge is, therefore, to establish to what extent combination of both physiological and metabolic models might be involved on different growth potential of mussels under study.

We are grateful to Lourdes Nieto, Beatriz González and Elsa Pena for technical assistance. The authors are also indebted to the crew of 'José María Navaz' from Instituto Español de Oceanografía. We are grateful to Dr M. Frechette for the critical review of the manuscript and P.M.J. Herman for helping with size distribution analysis. This work was supported by Project CICYT MAR97-0592. J.M.F. Babarro is in grateful receipt of a postdoctoral fellowship from Ministerio de Educación y Ciencia, Spain (1999-2001). 


\section{REFERENGES}

Babarro, J.M.F., 1998. Bases fisiológicas del crecimiento diferencial de la semilla de mejillón (Mytilus galloprovincialis, Lmk) de colector e intermareal, cultivada en batea. $\mathrm{PhD}$ thesis, University of Santiago de Compostela, Galicia, Spain. [In Spanish.]

Babarro, J.M.F., Fernandez Reiriz, M.J. \& Labarta, U., 2000a. Growth of seed mussel (Mytilus galloprovincialis Lmk): effects of environmental parameters and seed origin. Journal of Shellfish Research, 19, 187-193.

Babarro, J.M.F., Fernandez Reiriz, M.J. \& Labarta, U., 2000b. Feeding behaviour of seed mussel Mytilus galloprovincialis: environmental parameters and seed origin. Journal of Shellfish Research, 19, 195-201.

Babarro, J.M.F., Fernandez Reiriz, M.J. \& Labarta, U., 2000c. Metabolism of the mussel Mytilus galloprovincialis from two origins in the Ría de Arousa (north-west Spain). Fournal of the Marine Biological Association of the United Kingdom, 80, 865-872.

Bayne, B.L., 1999. Physiological components of growth differences between individual oysters (Crassostrea gigas) and a comparison with Saccostrea commercialis. Physiological and Biochemistry Zoology, 72, 705-713.

Bayne, B.L., 2000. Relations between variable rates of growth, metabolic costs and growth efficiencies in individual Sydney Rock Oysters (Saccostrea commercialis). Fournal of Experimental Marine Biology and Ecology, 251, 185-203.

Bayne, B.L., Svensson, S. \& Nell, J.A., 1999. The physiological basis for faster growth in the Sydney Rock Oyster, Saccostrea commercialis. Biological Bulletin. Marine Biological Laboratory, Woods Hole, 197, 377-387.

Bayne, B.L. \& Widdows, J., 1978. The physiological ecology of two populations of Mytilus edulis L. Oecologia, 37, 137-162.

Box, G.E.P., Hunter, W. \& Hunter, J.S., 1989. Estadística para investigadores. Introducción al diseño de experimentos, análisis de datos y construcción de modelos, ed. S.A. Reverté, Barcelona, 675 pp. (In Spanish.) From original English version: Statistics for experimenters. An introduction to design, data analysis and model building, (C) John Wiley \& Sons, Inc.

Dame, R.F., 1996. Organismic level processes. In The ecology of marine bivalves. An ecosystem approach (ed. R.F. Dame), pp. 35-74. CRC Marine Science Series, CRC Press, Inc.

Dickie, L.M., Bourdreau, P.R. \& Freeman, K.R., 1984. Influences of stock and site on growth and mortality in the blue mussel (Mytilus edulis). Canadian Fournal of Fisheries and Aquatic Sciences, 41, 134-140.

Fuentes, J., Molares, J. \& Villalba, A., 1998. Growth, mortality and parasitization of mussles cultivated in the Ría de Arousa (NW Spain) from two sources of seed: intertidal rocky shore vs collector ropes. Aquaculture, 162, 231-240.
Fuentes, J., Reyero, I., Zapata, C. \& Alvarez, G., 1992. Influence of stock and culture site on growth rate and mortality of mussels (Mytilus galloprovincialis Lmk.) in Galicia, Spain. Aquaculture, 105, 131-142.

Iglesias, J.I.P., Pérez Camacho, A., Navarro, E., Labarta, U., Beiras, R., Hawkins, A.J.S. \& Widdows, J., 1996. Microgeographic variability in feeding, absorption and condition of mussels (Mytilus galloprovincialis Lmk.): a transplant experiment. Journal of Shellfish Research, 15, 673-680.

Mallet, A.L., Carver, C.E.A., Coffen, S.S. \& Freeman, K.R., 1987. Winter growth of the blue mussel Mytilus edulis L.: importance of stock and site. Fournal of Experimental Marine Biology and Ecology, 108, 217-228.

Navarro, E., Iglesias, J.I.P., Pérez Camacho, A., Labarta, U. \& Beiras, R., 1991. The physiological energetics of mussels (Mytilus galloprovincialis Lmk.) from different cultivation rafts in the Ría de Arosa (Galicia, N.W. Spain). Aquaculture, 94, 197-212.

Page, H.M. \& Hubbard, D.M., 1987. Temporal and spatial patterns of growth in mussels Mytilus edulis on an offshore platform: relationships to water temperature and food availability. Fournal of Experimental Marine Biology and Ecology, 111, 159-179.

Pérez Camacho, A., Gonzalez, G. \& Fuentes, J., 1991. Mussel culture in Galicia (NW Spain). Aquaculture, 94, 263-278.

Pérez Camacho, A., Labarta, U. \& Beiras, R., 1995. Growth of mussels (Mytilus edulis galloprovincialis) on cultivation rafts: influence of seed source, cultivation site and phytoplankton availability. Aquaculture, 138, 349-362.

Peterson, C.H. \& Beal, B.F., 1989. Bivalve growth and higher order interactions: importance of density, site and time. Ecology, 70, 1390-1404.

Rawson, P.D. \& Hilbish, T.J., 1991. Genotype-environment interaction for juvenile growth in the hard clam Mercenaria mercenaria (L.). Evolution (USA), 45, 1924-1935.

Snedecor, G.W. \& Cochran, W.G., 1989. Statistical methods, eighth edn. Iowa State University Press.

Sukhotin, A.A. \& Maximovich, N.V., 1994. Variability of growth rate in Mytilus edulis L. from the Chupa Inlet (The White Sea). Fournal of Experimental Marine Biology and Ecology, 176, 15-26.

Widdows, J., Donkin, P., Salked, P.N., Cleary, J.J., Lowe, D.M., Evans, S.V. \& Thomson, P.E., 1984. Relative importance of environmental factors in determining physiological differences between two populations of mussels (Mytilus edulis). Marine Ecology Progress Series, 17, 33-47.

Submitted 8 April 2002. Accepted 21 November 2002. 